\title{
Estimation of Productivity in Korean Electric Power Plants: A Semiparametric Smooth Coefficient Model*
}

\author{
Almas Heshmati ${ }^{\mathrm{a} *}$, Subal C. Kumbhakar ${ }^{\mathrm{b}}$ and Kai Sun ${ }^{\mathrm{c}}$ \\ a Jönköping University, Jönköping, Sweden and \\ Department of Economics, Sogang University, Room K526, \\ Sinsu-dong \#1, Mapo-gu, Seoul 121-742 Korea, \\ E-mail: heshmati@sogang.ac.kr \\ ${ }^{\mathrm{b}}$ Department of Economics, Binghamton University, \\ Binghamton, NY 13902, USA, E-mail: kkar@binghamton.edu \\ ${ }^{c}$ Aston Business School, Aston University, \\ Birmingham, B4 7ET, UK, E-mail: k.sun@aston.ac.uk
}

December 19, 2013

Revised June 27, 2014

\begin{abstract}
This paper analyzes the impact of load factor, facility and generator types on the productivity of Korean electric power plants. In order to capture important differences in the effect of load policy on power output, we use a semiparametric smooth coefficient (SPSC) model that allows us to model heterogeneous performances across power plants and over time by allowing underlying technologies to be heterogeneous. The SPSC model accommodates both continuous and discrete covariates. Various specification tests are conducted to compare performance of the SPSC model. Using a unique generator level panel dataset spanning the period 1995-2006, we find that the impact of load factor, generator and facility types on power generation varies substantially in terms of magnitude and significance across different plant characteristics. The results have strong implications for generation policy in Korea as outlined in this study.
\end{abstract}

Keywords: Semiparametric estimation; smooth varying-coefficient model; electricity generation; generator level panel data

JEL Classification Numbers: C14; C23; C51; D24; L25; L94;

\footnotetext{
* Corresponding author
} 


\section{Introduction}

Semiparametric and nonparametric estimation techniques have in recent years attracted much attention from applied researchers ( $\mathrm{Li}$ and Racine, 2007 and 2010). Their attractiveness is attributed to their flexibility in capturing heterogeneous responsiveness of decision making units with minimum distributional assumptions. Robinson (1988) and Stock (1989) are prime examples of semiparametric and nonparametric models where the functional form of the nonparametric part is not specified. Fan and Li (1996) and Park et al. (1998) provide empirical panel data examples of semiparametric approaches, while the time series smooth transition autoregressive (STAR) model version of the smooth coefficient models introduced by Chen and Tsay (1993) and Hastie and Tibshirani (1993) suggest ways to estimate the unknown time varying smooth coefficient functions.

The semiparametric models are generalized in Li et al. (2002) in the context of production function to include a semiparametric smooth coefficient (SPSC) model formulation estimated via kernel method. In such a model the input coefficients are specified as unknown smooth functions of firm's R\&D input. The model follows the generalized knowledge production function of Griliches $(1979,1986)$. In an application based on Chinese industry data, Li et al. (2002) find the semiparametric model is more flexible than a parametric model. In addition it requires smaller sample size to obtain reliable estimation compared to its non-parametric counterpart. The issue of regional heterogeneity and impact of R\&D on productivity of high tech industry at the provincial level in China is investigated by Zhang et al. (2012) using a semiparametric approach. In their model the impact of R\&D on output is found to vary across different regions.

Recently Li and Racine (2010) proposed a semiparametric varying-coefficient model that admits both qualitative and quantitative covariates in specification of the varying coefficients along with a test for correct specification of the parametric varying-coefficient models. In this paper we use their approach that allows us to model heterogeneities across power plants and over time in order to capture important differences in the effect of load policy on power output that arise from public energy policy in Korea. The model accommodates both continuous and discrete covariates. Various specification tests are 
conducted to compare its performance relative to both of the conventional semiparametric and standard parametric models. Using a unique generator level panel dataset spanning the period 1995-2006, we find that the impact of load factor, generator and facility types on power generation varies substantially across different plant characteristics. The results are useful for the public energy policy in Korea.

The remainder of this study is organized into the following sections. Section 2 is a review of the electricity market in Korea. Section 3 is dedicated to data description and Section 4 to semiparametric estimation of the electricity generation model. Section 5 discusses the results that are presented for each methodology, grouped by time-invariant firm characteristics. Finally, a summary and conclusion are provided.

\section{The Korean Electric Power Industry}

The energy sector in Korea has expanded greatly due to its crucial role in supporting the economic development over the past 40 years. The country has experienced a rapid growth of electricity generation and subsequent structural change in the electricity market. In the process of economic development, the world oil crisis led Korea to pursue diversification of its energy sources. Main primary energy sources for generating electricity have been diversified into coal, oil, liquefied natural gas (LNG), and nuclear. In recent years, there is great public interest in developing renewable energy sources. The choice of energy has, however, been constrained by the large-scale investment in power plants and equipment under the long-term demand forecast.

Korea is highly dependent on imports of primary energy to meet its continuously increasing energy demand. The country has limited supplies of indigenous natural, primary and final energy resources. It has no domestic oil resources and only a very small amount of natural gas that has been produced locally. Recognizing its high dependence on external sources of energy, the country has successfully managed to satisfy its energy needs and diversify its energy use to reduce risk and vulnerability. The energy situation has a critical impact on the export oriented national economy as power consumption in Korea is 
continuously increasing with the growth of the economy. Another problem that needs to be considered seriously regarding the Korean electricity market is that the imported energy is from a small number of source countries, leading to a high level of vulnerability and insecurity in the energy supply. Korea not only ranks fifth among oil importing countries, but also is a significant importer of LNG. In this situation the electricity market has to operate under optimal conditions in order not to face a shortage. The most fundamental way to secure the energy supply is to raise the efficiency and productivity of the generation, transmission and distribution stages of the electricity industry.

Many countries have taken restructuring or reforms to facilitate competition as a solution to enhance the productivity of their electricity markets. Over 76 countries worldwide are currently implementing or planning to implement a reorganization of their electricity industries. The vertically monopolized structure of the electricity industry, in which only one company takes charge of all the processes in the generation, transmission, distribution, and market sale, is now radically changing. In order to examine the present status of overseas electricity industry reorganization, Horwath Choongjung Consulting and Seoul National University Engineering Lab (HCC-SNUEL, 2008) conducted a study analysing the market in seven countries, which are the UK, Nord Pool (Norway, Sweden, Finland, and Denmark), the US, Spain, Australia, France, and Japan. Examination of the different markets reorganizations led to a number of conclusions. The reorganization process should progress but not be associated with price cuts. Facility investment needs which are under long-term plan be supplemented with support by the government. A consideration of environmental problems and alternative energy is urgently needed.

In an attempt to reform the electricity industry to overcome the problem of the KEPCO (Korea Electric Power Corporation) monopoly, the power generation sector in Korea was transformed into a competitive system. As a result of such efforts, KEPCO was separated into six GENCOs (Generation Companies) in 2001, but it still retains the national transmission and distribution grids, and it owns all of the six GENCOs. At the same time, a power market, the state-owned Korea Power Exchange (KPX), was established. While liberalization remains a key policy goal of the government, it has not been able to establish 
timetables for these halted liberalization efforts.

The HCC-SNUEL (2008) study analysed performance of the generation part of the Korean electricity market. The objective was to compare performance before and after the separation. They used three methods: process benchmarking methodology (PBM) to compare performance before and after reorganization, data envelopment analysis (DEA) to estimate efficiency, and Malmquist productivity index (MPI) to analyse efficiency change at each process. Stable supply and low generation cost has resulted from competition among the generation companies. Heshmati (2012) used parametric stochastic frontier analysis (SFA) as well as DEA and MPI for performance analysis. He found that the netgeneration is mainly affected by facility type, maintenance cost, real fuel cost, and other costs. When heterogeneity in efficiency is considered, the national generation plan is characterized by the high efficiency of nuclear plants, base type and large size facilities. The management efficiency was slightly lowered after the six GENCO were separated from KEPCO. Furthermore, efficiency enhancement from the restructuring effect is not clearly distinguished when comparing periods before and after restructuring.

Through maintaining a stable supply of energy, the Korean government has provided the long-term energy policy directions and information on electricity supply and demand. In this regard, the First Basic Plan of National Energy (MKE, 2008a) and the Fourth Basic Plan of Long-term Electricity Supply and Demand (MKE, 2008b) were introduced to secure the electricity supply. Korea's overall energy policies seek to achieve a sustainable development through energy security, energy efficiency, and environmental protection. The government has not only accelerated the policies and measures for energy efficiency linked with a carbon abatement measure, but also considered transition of the market. The desired transition is from the current energy system, which centres on a concentrated supplyoriented system, toward a sustainable energy system, which involves the elements of a distributed demand-oriented system.

Power consumption is steadily increasing in Korea. In spite of a decline in the growth rate since the early 1990s, the average power consumption per capita is relatively high in comparison with other OECD members. The industry sector is the largest consumer, 
accounting for $53 \%$ of the total amount of generated electricity in 2007 . In terms of the price, electricity for the agriculture sector is the cheapest due to government subsidies. The Korean electricity market uses a cost-based pool system. The price system differs depending on the type of generator and the inclusion or exclusion of unconstrained supply schedules. The structure of the electricity market involves stages from generation via transmission and distribution to consumers.

At an early stage, the electricity market was made up of only seven members in the trading market, including KEPCO and the six GENCOs. In late 2008, there were 302 members who participated in the market. Based on the amount of transactions for each energy source, nuclear, coal, and LNG are the top three primary sources since 2001. However, the ranking changes over time due to fluctuations in the different source prices. In 2007 power generation from coal power plants was first and nuclear power plants were in the second position. The third position was held by the combined cycle power plant. In the field of combined cycle power plants, many private companies operated the plants, but the share of GENCOs was much higher. The Korea Hydro and Nuclear Power (KHNP) operates 20 nuclear power plants commercially. Hydro power plants generated only $1.0 \%$ of the total power generation. The proportion of new and renewable energy sources is very small, $2.24 \%$ of the total generation. The low proportion was mainly because they lacked profitability compared to conventional energy resources. The Korean government aimed to increase the proportion to $5.0 \%$ by 2011 .

In relation with the regulations and agreements such as the Kyoto protocol, several strategies are being put into action. The adequacy of generation mix against environmental change is under consideration. The government aims to contribute to the expansion of renewable energy sources by reflecting the related facilities in its decisions. Optimization of resource utilization for demand side management is taking into consideration the status of the electricity balance. All trends demonstrate that the Korean electricity industry is changing its character. These dynamic situations require the generation companies to invest more effort in research and development $(\mathrm{R} \& \mathrm{D})$ and to cooperate in development of the efficient and low-cost generation technologies. Previous analysis of the industry was 
carried out by Choi and Ang (2002), Lee and Ahn (2006), and Park and Lesourd (2000).

The review above elaborated with the past situation of the Korean electric market and electricity policy. Currently the energy market and policy have been affected by recent changes in energy markets including Fukushima nuclear power plant accident and shale gas revolution affecting the fuel mix. The recent future of Korean electric market is discussed in a number of studies. Hayashi and Hughes (2013) examine the crisis-driven changes to energy security, energy policy and regulations in the immediate aftermath of the Fukushima accident. Min and Chung (2013) present a portfolio for the long-term power generation to optimize the power generation mix. The authors evaluate LNG and coal as cost effective alternatives to reduce dependency on nuclear. Shin et al. (2014) also find increasing acceptability for renewable portfolio standard in Korea. Ryu et al. (2014) discuss electricity generation mix by considering energy security, energy cost and carbon emission mitigation. The appropriate portion of nuclear energy is the determining policy factor. Kim et al. (2011) in looking at trends in energy demand, supply, policies and security find that nuclear power continues to hold a crucial position in the energy policy, but nuclear power expansion will not be sufficient to attain the "green economy" and greenhouse gas emission reduction goals. Baek and Kim (2013) confirm the positive effect of GDP growth on environmental outcomes. The issues of diffusion of five renewable energy technologies and their competitive interrelationships is discussed in Huh and Lee (2014). To support the renewable energy diffusion pattern and to overcome policy limitations, Korean government is recommended to implement new and technology specific policies. Park and Kim (2014) view the Fukushima accident as a key factor influencing the public attitude-intention towards use of renewable energy sources and technologies with implications for affordability of energy for Korean companies (Suk et al. 2014). Kim et al. (2014) find that growth of renewable technology and its penetration level is proportional to cumulative $\mathrm{R} \& \mathrm{D}$ investment indicating the necessity of more active supportive public investment policies.

\section{The Data}


The data used in this study are obtained from the HCC-SNUEL (2008) and consists of a sample of 171 of generators which are observed during the period from 1995 to 2006. The panel data is unbalanced. Generators are observed at most 12 years. The total number of observations is 1,637. All monetary values are expressed in fixed 2000 prices.

The data contains output, inputs and generator characteristics. All variables used here and their definitions are as described below. We used generation quantity (Gen) as output measured in MWh. The regressors include facility capacity which measure capital (K), maintenance cost $(M)$, sale expenditure $(S)$, primary fuel cost $(F)$, other costs $(O)$, wages (W), and time trend (Trn). These inputs are in logarithmic form, except the time trend variable which is included in the parametric part to capture technical change. The characteristic variables include number of generators (NG) in a plant, age of generator (Age), facility type (FT) including base load (type=1), middle load (type=2), and Peak load (type=3), dummy for positive facility capacity $(\mathrm{dK})$, dummy for positive primary fuel type $(\mathrm{dF})$, and dummy for positive wage (dW) are introduced to capture effect of zero-valued variables. Total generation cost is defined as the sum of fuel cost, wages, sales and management expenditure, and other costs. The summary statistics of the data set are reported in Table 1.

Table 1. Summary statistics of the electricity generation data, 1995-2006, $\mathrm{n}=1637$.

\begin{tabular}{|l|r|r|}
\hline Variable & \multicolumn{1}{|c|}{ Mean } & \multicolumn{1}{c|}{ Std. Dev. } \\
\hline Electricity generation (MWh) & $1,940,094$ & $2,299,155$ \\
\hline Facility capacity (MW) & 328 & 272 \\
\hline Maintenance cost (million won) & 1,676 & 2,061 \\
\hline Sales and management expenditure (million won) & 1,128 & 1,279 \\
\hline Other costs $^{1)}$ (million won) & 46,064 & 59,826 \\
\hline O\&M cost $^{2)}$ (million won) & 42,549 & 59,519 \\
\hline O\&M unit cost ${ }^{3)}$ (won/kWh) & 71 & 576 \\
\hline Real fuel cost (1000 USD) & 38,839 & 39,217 \\
\hline Wages (million won) & 2,915 & 3,163 \\
\hline Age of generator & 17 & 15 \\
\hline
\end{tabular}

(1) Other costs $=($ total cost) - (fuel cost) - (wage) - ( sales and management expenditure); (2) O\&M cost = (sales and management expenditure $)+($ other cost $) ;(3) \mathrm{O} \& \mathrm{M}$ unit cost $=(\mathrm{O} \& \mathrm{M} \operatorname{cost}) /($ net generation $)$. 


\section{Econometric Model}

We use a production function to examine the relationships between output, inputs and production environmental characteristics. The logarithmic transformation of a production function linearizes the production relation with respect to the unknown parameters. Instead of including the environmental and production characteristic factors (Z) additively and estimate the model using ordinary least squares (OLS), we include them into the coefficients in our semiparametric model. The semiparametric production function (using panel data) that we estimate is of the form:

$$
\begin{aligned}
\log \operatorname{Gen}_{i t}= & \beta_{0}\left(Z_{i t}\right)+\beta_{1}\left(Z_{i t}\right) \log \left(K_{i t}\right)+\beta_{2}\left(Z_{i t}\right) \log \left(M_{i t}\right)+\beta_{3}\left(Z_{i t}\right) \log \left(S_{i t}\right) \\
& +\beta_{4}\left(Z_{i t}\right) \log \left(F_{i t}\right)+\beta_{5}\left(Z_{i t}\right) \log \left(O_{i t}\right)+\beta_{6}\left(Z_{i t}\right) \log \left(W_{i t}\right)+\beta_{7}\left(Z_{i t}\right) \operatorname{Trn}_{i t}+u_{i t}
\end{aligned}
$$

where $i$ indexes generator and $t$ indexes time; $u_{i t}$ is zero mean i.i.d. random disturbance term. The dependent output variable is quantity of generated electricity (Gen) and the independent input variables include generation capacity $(\mathrm{K})$, maintenance cost $(\mathrm{M})$, sales expenses (S), primary fuel cost $(\mathrm{F})$, other expenses $(\mathrm{O})$ wages $(\mathrm{W})$, and time trend $(\mathrm{Trn})$. All the coefficients (i.e., intercept and slopes) are some unknown functions of the vector of $\mathrm{Z}$ variables:

$$
Z_{i t}=\left(N G_{i t}, A g e_{i t}, F T_{i t}, d K_{i t}, d F_{i t}, d W_{i t}\right) .
$$

The $\mathrm{Z}$ variables include number of generators per plant (NG), age of generator (Age), facility type (FT) with three categories, dummies for facility capacity $(\mathrm{dK})$, fuel cost (dF) and wages ( $\mathrm{dW}$ ) to capture the effect of non-zero valued variables. This model follows the approach of Li et al. (2002) and Zhang et al. (2012) where a number of environmental variables included in $\mathrm{Z}$ affect the firm's ability to transform inputs into outputs. If the shift in production function is neutral these environmental factors can be introduced in the intercept parameter and if non-neutral they influence productivity via all other covariates as in (1). In such case the environmental variables affect input elasticities in a flexible manner. For a given level of environmental factor, the model is reduced to the standard constant coefficient Cobb-Douglas production model.

The generalized production model in (1) can be written more compactly as: 


$$
Y_{i t}=X_{i t}^{\prime} \beta\left(Z_{i t}\right)+u_{i t}
$$

where $Y_{i t}=\log \left(G e n_{i t}\right), X_{i t}=\left[1, \log \left(K_{i t}\right), \log \left(M_{i t}\right), \log \left(S_{i t}\right), \log \left(F_{i t}\right), \log \left(O_{i t}\right), \log \left(W_{i t}\right), T r n_{i t}\right]$, and $\beta^{\prime}\left(Z_{i t}\right)=\left[\beta_{0}\left(Z_{i t}\right), \beta_{1}\left(Z_{i t}\right), \ldots, \beta_{7}\left(Z_{i t}\right)\right]$. Following Li et al. (2002), the semiparametric estimator of the functional coefficients can be written as:

$$
\hat{\beta}\left(Z_{i t}\right)=\left[\sum_{j=1}^{N} \sum_{\tau=1}^{T} X_{j \tau} X_{j \tau}^{\prime} K\left(Z_{j \tau}, Z_{i t}\right)\right]^{-1} \sum_{j=1}^{N} \sum_{\tau=1}^{T} X_{j \tau} Y_{j \tau} K\left(Z_{j \tau}, Z_{i t}\right),
$$

where $\mathrm{N}$ and $\mathrm{T}$ denotes the number of cross-sections and time periods, respectively, $\mathrm{K}($.$) is$ a generalized kernel function (Racine and Li, 2004). Here we define $Z_{i t}=\left[Z_{i t}^{c}, Z_{i t}^{d}\right]$, where $Z_{i t}^{c}=\left[N G_{i t}, A g e_{i t}\right]$ is a vector containing continuous variables, and $Z_{i t}^{d}=\left[F T_{i t}, d K_{i t}, d F_{i t}, d W_{i t}\right]$ is a vector of categorical and dummy variables. The kernel function $\mathrm{K}($.) can then be explicitly written as:

$$
K\left(Z_{j \tau}, Z_{i t}\right)=\prod_{s=1}^{2} K^{c}\left(\frac{Z_{s j \tau}^{c}-Z_{s i t}^{c}}{h_{s}}\right) \prod_{r=1}^{4} K^{d}\left(Z_{r j \tau}^{d}, Z_{r i t}^{d}, \lambda_{r}\right),
$$

where

$$
K^{c}(.)=\frac{1}{\sqrt{2 \pi}} \exp \left(-\frac{1}{2}\left(\frac{Z_{s j \tau}^{c}-Z_{s i t}^{c}}{h_{s}}\right)^{2}\right)
$$

and

$$
K^{d}(.)= \begin{cases}1-\lambda_{r} & \text { if } Z_{r j \tau}^{d}=Z_{r i t}^{d} \\ \lambda_{r} /(c-1) & \text { otherwise }\end{cases}
$$

where, in our application, c, the number of categories, is equal to two, for dummy variables that take the value of 0 or 1 . The $h_{s} \forall s=1,2$ are the bandwidths for each continuous variable in $Z_{i t}^{c}$, and $\lambda_{r} \forall r=1,2,3,4$ are the bandwidths for each discrete variable in $Z_{i t}^{d}$. They are selected by minimizing the objective function: 
(8) $\quad \sum_{i=1}^{N} \sum_{t=1}^{T}\left[Y_{i t}-X_{i t}^{\prime} \hat{\beta}_{-i t}\left(Z_{i t}\right)\right]^{2}$,

where

$$
\hat{\beta}_{-i t}\left(Z_{i t}\right)=\left[\sum_{j \neq i}^{N} \sum_{\tau \neq t}^{T} X_{j \tau} X_{j \tau}^{\prime} K\left(Z_{j \tau}, Z_{i t}\right)\right]^{-1} \sum_{j \neq i}^{N} \sum_{\tau \neq t}^{T} X_{j \tau} Y_{j \tau} K\left(Z_{j \tau}, Z_{i t}\right) .
$$

$\beta\left(Z_{i t}\right)$ in equation (3) can be interpreted as input elasticities since $\beta\left(Z_{i t}\right)=\partial Y_{i t} / \partial X_{i t}$ where both $Y_{i t}$ and $X_{i t}$ are in logarithmic forms. One can also measure the marginal effect of $Z_{i t}^{c}$ on $Y_{i t}$ since $\partial Y_{i t} / \partial Z_{i t}^{c}=X_{i t}^{\prime}\left[\partial \beta\left(Z_{i t}\right) / \partial Z_{i t}^{c}\right]$. The marginal effect of $Z_{i t}^{d}$ on $Y_{i t}$, on the other hand, can be calculated via the finite difference $Y_{i t}\left(Z_{r i t}^{d}=1\right)-Y_{i t}\left(Z_{r i t}^{d}=0\right), \forall r=1,2,3,4$.

It is worth mentioning that we can test whether $\beta$ in (3) is indeed an unknown function of $Z$. That is, we can test the null hypothesis:

$\mathrm{H}_{0}: \beta\left(Z_{i t}\right)=\beta_{0}\left(Z_{i t} ; \theta_{0}\right)$

where $\theta_{0}$ is a parameter vector that can possibly have zero-valued slopes and a non-zero intercept. The model under the null can thus be written as:

(10) $Y_{i t}=X_{i t}^{\prime} \beta\left(Z_{i t} ; \theta_{0}\right)+e_{i t}$.

Following $\mathrm{Li}$ and Racine (2010), the consistent model specification test statistic is constructed as:

(11) $\quad \hat{I}_{N T}=\frac{1}{(N T)^{2}} \sum_{j=1}^{N} \sum_{\tau=1}^{T} \sum_{i \neq j}^{N} \sum_{t \neq \tau}^{T} X_{j \tau}^{\prime} X_{i t} \hat{e}_{j \tau} \hat{e}_{i t} K\left(Z_{j \tau}, Z_{i t}\right)$,

where $\hat{e}_{i t}=Y_{i t}-X_{i t}^{\prime} \hat{\beta}\left(Z_{i t} ; \theta_{0}\right)$ are the residuals from (10). $\beta_{0}\left(Z_{i t} ; \theta_{0}\right)$ can be specified as either a constant or any parametric functions such as a function that is linear in $Z$ and $\theta_{0}$. We then use the residual-based wild bootstrap method ( $\mathrm{Li}$ and Racine 2010) to determine whether to reject the null hypothesis or not. To do this, we first estimate (10) via OLS and 
obtain the fitted values $\left(\hat{Y}_{i t}\right)$ and residuals. The wild bootstrap disturbance, $e_{i t}^{*}$, is generated such that $e_{i t}^{*}=[(1-\sqrt{5}) / 2] \hat{e}_{i t}$ with probability $(\sqrt{5}+1) /(2 \sqrt{5})$, and $e_{i t}^{*}=[(1+\sqrt{5}) / 2] \hat{e}_{i t}$ with probability $(\sqrt{5}-1) /(2 \sqrt{5})$. A new dependent variable can then be generated using the old fitted values, $\hat{Y}_{i t}$, and the new residuals, $e_{i t}^{*}$. The new sample is then used to estimate the parametric model (10), and the residuals can be obtained. These residuals are used to construct the bootstrap statistic, $\hat{I}_{N T}^{*}$, using (11). Finally, re-generate the bootstrap disturbance and then re-calculate $\hat{I}_{N T}^{*}$ a large number of times, say, B=399 times, and a pvalue is obtained as $\frac{1}{B} \sum_{b=1}^{B} \mathrm{I}\left(\hat{I}_{N T}^{b^{*}}>\hat{I}_{N T}\right)$, where $\mathrm{I}($.$) is the indicator function with a value of 1$ if the statement in the parentheses is true, and $\hat{I}_{N T}^{b *}$ is the bootstrap statistic from the $b$-th replication. The null hypothesis can be rejected if the p-value is less than the level of significance, say, 0.05 .

\section{Estimation Results}

\subsection{Specification tests}

In order to identify and estimate a better model, several model specifications are formulated and estimated. These models are nested and as such testable against each other. It seems more appropriate to start from a simple Cobb-Douglas model and generalize it stepwise to the following set of nested models.

The first model (Model 1) is a simple Cobb-Douglas production model where output is modeled as function of inputs. Here plant characteristics and environmental variables $(\mathrm{Z})$ are introduced in the intercept $\beta_{0}\left(Z_{i t} ; \theta_{0}\right)$ which is specified as a linear function with $\theta_{0}$ as the parameter vector. The advantage of this model over the basic traditional model without the $\mathrm{Z}$ variables is that it allows for plant heterogeneity by specifying the intercept as a parametric function of various environmental factors which can be both continuous and discrete. The model is estimated by using ordinary least squares (OLS) method where the 
marginal effects of the $\mathrm{Z}$ variables on the intercept is its corresponding estimated constant parameters.

The second model (Model 2) is a generalized production model where both intercept and slope parameters vary with plant characteristics and production environmental variables. Model 2 is a generalization of Model 1 in which the coefficients are linear parametric functions of the $\mathrm{Z}$ variables implying non-neutral parametric shift in the production function. The model still can be estimated parametrically and by the OLS method. ${ }^{1}$

The final model (Model 3) is a further generalization of the production model (equation 1) in which, similar to Model 2, both intercept and slope parameters vary with plant characteristics and production environmental variables. The difference with Model 2, however, is that the intercept as well as the slope coefficients are unknown smooth functions of the $\mathrm{Z}$ variables implying nonparametric non-neutral shift in the production function. These functional coefficients are estimated nonparametrically using semiparametric smooth coefficient model via local constant least squares procedure introduced in Li et al. (2002) and Li and Racine (2010).

It is worth mentioning that the smooth coefficient model (Model 3) which includes the kernel function (equation 5) can reduce to the traditional Cobb-Douglas production function with constant elasticities (Model 1). A model specification test of Model 1 against Model 3 (Li and Racine, 2010) rejects the simple parametric Cobb-Douglas production model with constant slopes at the $1 \%$ level, supporting the semiparametric Model 3 with parametric heterogeneous intercept and slopes. Given this, the rest of the analysis focuses on Model 3 results.

\subsection{Parametric results}

The estimation results from Model 1 and Model 3 are presented in Tables 2A and 2B. In order to conserve space, we do not report results from Model 2. These tables summarize

\footnotetext{
${ }^{1}$ Not all parameters from the intermediate Model 2 are identifiable because of the singularity problem (i.e., multicollinearity). For example, $\mathrm{dK}^{*} \log (\mathrm{K})$ is computationally collinear with $\log (\mathrm{K})$ because $\mathrm{dK}$ is almost always equal to one. Results from Model 2 are not reported here.
} 
the estimation and elasticity results from the two models with respect to facility capacity, maintenance cost, sales and management expenses, fuel cost, other costs, wages and technical change.

The results from Model 1 represents only neutral shift in the production function. It shows that facility capacity representing elasticity of output with respect to capital is the highest (0.7803) followed by fuel cost (0.6274) and sales and management expenses (0.2402). The output elasticity with respect to maintenance and other costs are lower, 0.0702 and 0.0800 , respectively. All these elasticities are as expected positive and statistically significant at the less than 5 percent level of significance. The rate of technological change is negative (0.0510) suggesting technical regress which might be attributed to lowered generation intensity per plant, costly improved energy security and greater emphasis on demand management policies. The output elasticity of labor represented by wage cost is negative (0.1435). The latter two elasticities are of unexpected sign. The negative labor elasticity in the short run might be due to labor hoarding or increasing construction capacity without any generation or costly enhanced plant security.

The coefficients of the characteristic variables representing a neutral shift in the production function are reported in Table 2B. The sign of number of generators is negative, thereby meaning that more generators reduce the intensity of their use individually. Age of generators has a positive effect possibly due to learning by doing and improved capacity utilization over time. The facility types medium and peak loads are negative, as expected indicating basic load being more responsive to total amount of electricity generation. The dummy variables related to zero values of facility capacity, fuel cost and wages are all significant suggesting corrections for possible selection bias.

\subsection{Semiparametric results}

Unlike the restrictive Model 1, Model 3 gives observation specific parameter estimates. In order to compress the result, we report the estimates at the mean, $25^{\text {th }}, 50^{\text {th }}$ (median) and $75^{\text {th }}$ percentiles and their respective standard errors. At a later stage we report the results by 
different plant characteristics to investigate performance heterogeneity across the plants. As it is shown in Table 2A with the exception of the intercepts, all slope coefficients are statistically significant at the 5 percent level or lower.

In general, the average results across the two models are consistent with each other and of the expected signs. However, in few cases differences and in their variations are found across the two models. Comparison of the OLS with (mean) semiparametric elasticities we note that the coefficient of maintenance cost is negative $(-0.0089)$ which is in violation of the regulatory conditions. Another key difference is with size of the intercept and lower mean elasticity of output with respect to capacity utilization (0.5582) and wages (-0.0117). The other output elasticities among the two models differ marginally. The rate of technical regress is one percentage point lower in the semiparametric model.

Considering the semiparametric model and heterogeneity in outputs responses to changes in the inputs we note that mean and median differs suggesting skewed distribution in the output elasticities. This applies to the rate of technical change as well. The mean and median values of output elasticity with respect to wages differ in sign indicating largest skewness to the left tail of the distribution. The largest gaps, ranked by the order of magnitude, are attributed to wages, sales and management expenses, facility capacity and lastly to fuel cost. The large gaps between the first and third quartiles suggest large dispersion in most output elasticities and the rate of technical change. This is supported by the fact that for maintenance costs, other costs and wage, the sign of the elasticity changes from negative to positive when the two quartiles are compared.

The partial derivatives of output with respect to the characteristic factors $(Z)$ are reported in Table 2B for both models. The characteristics include the number of generators at a plant, their average age, facility type in respect with generation load, and a number of dummy variables indicating zero values of facility capacity, fuel cost and wages.

The marginal effects of the characteristic variables in the case of semiparametric model represent a non-neutral shift in the production function. The sign of marginal effect of number of generators at the mean is negative, meaning that as the number of generators increases the output per unit decreases, ceteris paribus. A negative marginal effect is not 
meaningful, but it is a result of reduced capacity utilization in use of some generators operating with for the time expensive energy type. Unlike in Model 1, the average age of generators in a plant has a negative effect. However, the effects of semi-continuous variables of number of generators per plant and age of generator are small and negligible. The signs of facility types of medium and peak loads are negative, as expected, indicating basic load more responsive to changes in the amount of electricity generation. The dummy variables related to zero values of facility capacity, fuel costs, are all statistically significant thereby distinguishing the neutral and non-neutral model specifications.

Similar to the distribution of the semiparametric coefficients, distributions of the partial derivatives of generation of electricity with respect to different plant characteristics differ substantially. Table 2B shows that the mean and median values of number of generators, age and facility capacity differs but less in magnitude compared with the output elasticities and compared with the zero characteristics dummy variables. The largest difference is attributed to dummy variables related to zero facility capacity and fuel costs. The gaps between the $1^{\text {st }}$ and $3^{\text {rd }}$ quartiles are much larger suggesting skewed distribution of these non-neutral shifters of production. Facility load type is the main shifter followed by fuel cost and wages.

\subsection{Heterogeneity by plant characteristics}

Similar to the large variations in the observation specific levels of output elasticities and partial effects of characteristics on production, there are also large variations in their averages across different generator characteristics and over time. The characteristics of interest include: number of generators per plant, average age of generator in years, fuel source, plant type, facility load type, percentage facility utilization rate, and holding time measured in hours per year. These are reported in Table $3 \mathrm{~A}$ and $3 \mathrm{~B}$. In order to conserve spaces, the point elasticity and marginal effects are not reported here.

A close look at the changes in the mean output elasticities of inputs over time (Table $3 \mathrm{~A}$ ) show that the output elasticity with respect to facility capacity (which is the largest) is 
declining over time, while the output elasticity in respect with fuel cost is increasing. The third largest output elasticity is that of sales and management expenditure which is declining. All of these three key output elasticities are positive in each year. Similar to these three cases where we find trends in their development over time, -- there is positive trend in the maintenance and other costs which switch from negative to positive in 2005/6 and 1997/8 respectively. The output elasticity of wages is small and mainly negative and without any trend in its development. The high yearly rate of technical regress ranges from 7.8 percent to 4.9 percent.

The partial effect with respect to fuel cost dummy is large, negative and declining over time. Similar negatively signed and trended partial effects are observed in relation with facility types of medium and peak loads compared with the base load which serves as reference load type. Marginal effect of facility capacity is relatively large and changed from negative to positive over time. The marginal wage effect is low and its mean value is volatile over time. The marginal effects of age and number of generator effect are small (see Table 3B).

The output elasticities of facility capacity, sales and management costs are negatively related to the number of generators, while fuel cost is positively related due to the fact that peak load generators are operating with high cost of primary fuel sources. There is also a positive relationship between output elasticity of wages and number of generators suggesting that wages at the peak load generators operating at the margin capacity is higher. The rate of technical regress in general increases with the number of generators per plant. Variations in the marginal effects of output with respect to generator characteristics are less systematic in relation to the number of generators per plant (see Tables $3 \mathrm{~A}$ and 3B).

The difference in the output elasticities across age cohort of generators is pronounced. The elasticity of output with respect to facility capacity is negatively correlated to the age of generator. Similar is the case with fuel cost, and wages, while it is positively correlated with maintenance cost and sales and management expenditures. Similar relationships are found between age and the marginal effects of generator characteristics. The number of 
generators, facility capacity, higher loads and facility dummy variable are all positively related, while age of generator and fuel cost dummy variables are negatively related.

The output elasticity of facility capacity is highest for nuclear, the two types of coals and hydro plants, while it is lowest for oil and gas driven plants which are used only as peak load. The sales and management expenditures is highest for hydro and gas plants. The fuel cost is the highest for gas and oil but lowest for hydro plants. The other cost elasticity with the exception of hydro which is surprisingly negative is almost of equal size. Oil and gas due to their high price level and their volatility contribute most to the technical regress. Considering the marginal effects, again hydro, oil and gas fuel driven generators are more responsive than those generators driven by nuclear and coal sources.

In the case of plant type, nuclear, combined cycle, hydro pump and internal combustion show the highest output elasticities with respect to facility capacity. The lowest output elasticity is related to gas turbine and small hydro type. In terms of fuel cost, the output elasticity is found to be high for gas turbine, hydro pump and small hydro, while it is low for combined cycle and negative for internal combustion. Internal combustion is the only plant type which shows technical progress, while remaining types are subject to technical regress, which the rate is highest for gas turbine type. Again we find large variations in the marginal effects across plant types. The main variations are attributed to load type and facility capacity and fuel cost dummy variable.

As expected the base load facility capacity has higher output elasticity, followed by the peak load and it is lowest for the middle load capacity. The low responsiveness for middle load capacity suggests that volatility in electricity demand is high which is mainly satisfied by the base and peak loads. The costs attributed to sale, management and fuel show large variations across different load capacities. It is as expected highest for the peak load. The output elasticity with respect to wages reflecting efficiency in use of labor at these plant types differs. It is negative for the peak load plants. The rate of technical regress is lowest for the middle load which is it capacity is utilized less. Similar results are found for the partial effects in the case of middle load. 
We note a clear difference between output elasticity of facility capacity and its rate of utilization. In particular the rate of technical regress is much higher for the plants with low rate of capacity utilization. We note lower differences in outputs responsiveness to changes in costs of fuel and sales and management expenditure. Again variation in the marginal effects is large in respect with degree of capacity utilization of generators/plants.

The last plant characteristic as source of heterogeneity is the generators holding time for repairs, services and malfunctions. We note the output elasticities with respect to the key factor of facility capacity and sales and management expenditure are inversely related to the holding time. A high maintenance cost affects the rate of holding time negatively. The rate of technical regress is much higher for the plants classified in the category with high holding times. Significant heterogeneity in the size of partial effects is also observed in respect with holding time of generators/plants operation.

\subsection{Policy implications of the results}

Unlike traditional models where supply response is practiced, in the deregulated electricity markets case demand response and its management is increasingly employed (Heshmati, 2013a). In situations with expansion of demand for electricity, it might be cheaper to reduce demand than to increase supply. This is evidenced in particular in cases where price is regulated below the cost of incremental supply which does not give incentives to consumers to conserve. In such cases, it is better for the utility to pay price corrections in exchange for consumer demand reductions to balance supply and demand. The collapse of oil prices in 1998-1999 led to increased capacity expansion and the following energy price surge led to excess capacity which further increased its cost coverage. These differences between supply and demand response and increased marginal cost for incremental supply explain the rate of technical regress in our results.

In line with the result here, several previously conducted studies (Heshmati, 2013b) show evidence of a decreasing trend in the performance in the electricity market. After separation in 2001 the DEA based efficiency is reduced slightly due to a lower scale 
efficiency change. The results show that, the efficiency of generating companies did not improve, as was expected, after the separation process. However, the magnitude of scale effect was increased after the separation. The MPI results suggest decreased efficiency over the period. By separating the period into before and after separation, one can see a slowly increasing pattern before 2001 while a gradually decreasing trend after 2001 . Inefficiency comes from scale efficiency in the before-restructuring time, while in the after-restructuring time it comes from decline in the technical change. This means there were not enough technological improvements in the electricity generation industry after 2001. In total, productivity declined over time which is consistent with our findings of technical regress.

Heshmati (2012) analyzes the technical efficiency of generation units, rank each unit for comparative assessment of their technical efficiency status and suggests policy recommendations. Although most of strategic activities for generation are decided by company or business unit levels, one can suggest suitable performance enhancement strategies and measures at the generator level. Based on the efficiency result, the effect from facility age or technological change was found to be small. Inefficiency of units is mostly related to the type of facility. It means that the market operating scheme is a basic factor in the operation performance. Although the facility type affects generation as the most important factor, in the view of control, the flexible labor management can be recognized as an easier way to introduce changes. More flexibility in human resource management in form of the labor transfer and labor pool of the same generation source or the same generation type facilities has been suggested. However, such reallocation of labor among generation companies is not an easy task in reality. The inflexible labor use in the generation may explain the low output elasticity of labor and for some segments irregularities in the labor coefficient.

The strategy for improving the effectiveness of the fuel factor is most urgent. The increased fuel price is very likely the most important factor attributed to productivity decrease. Thus, a stabilizing strategy in response to the volatile fuel price in the long term is required. That is, not only a low purchasing price but also a stabilization of fuel price is 
important measures to reduce variations in the efficiency and productivity levels. In this regard, the long term fuel purchasing and purchasing diversification should be considered. A reorganization of the electricity generation sector by the same fuel type can be a way to obtain high purchasing power. It can have fuel purchasing power under the unified simple energy source and also make the operational performance higher and organizational management easier.

\section{Summary and Conclusion}

Semiparametric varying-coefficient method used in the paper accommodates both qualitative and quantitative covariates in specification of the varying coefficients. In this paper we used the semiparametric approach to analyze the impact of load factor, facility and generator type and other characteristics on the productivity of Korean electric power plants. The model captures important heterogeneities in the effect arising from public energy policy across power plants and over time. Various specification tests are conducted to compare the model performance.

The tradition parametric models such as the Cobb-Douglas can be derived as a special case of the smooth coefficient model with constant elasticities. A model specification test rejects the simple parametric production model with constant slopes, supporting the semiparametric model with heterogeneous intercept and slopes. Using a unique generator level panel dataset, we find that the impact of load factor and generator and facility types on power generation varies substantially. The period of our study 1995-2006, which covers the electricity generation market restructuring period of 2001, allows us to examine the impact of reform on the performance of plants. The variations in the impact are large across different plant characteristics. This result is useful for the public energy policy in Korea.

The elasticity estimates from the two models with respect to facility capacity, fuel cost, wages, other inputs costs and technical change are provided. In general, the output elasticity results across the two models are consistent with each other, have expected signs 
and statistical significance. The results from simple and varying coefficient semiparametric models represent neutral and non-neutral shifts in the production function, respectively. The rate of technological change is negative suggesting technical regress which might be attributed to lowered generation intensity per unit, improved energy security and practice of demand management policies in the electricity market. The output elasticity of labor represented by wage cost is unexpectedly negative which might be due to labor hoarding, faster wage increases than labor productivity, increasing construction capacity and enhanced power plant security. The estimated effects of plant characteristics are as expected where increased number of generator reduce the intensity in their use individually. Age of generators has a positive effect indicating learning by doing over time. The facility types show that basic load being more responsive to total generation.

The smooth coefficient model gives rise to observation specific coefficient estimates. Summary of the result at different segments of the distribution suggest presence of heterogeneity in estimates by various plants characteristics. Large skewness in the distributions of output elasticities is also observed. The largest gaps are attributed to wages, sales and management expenses, facility capacity and fuel cost. The large gaps between the first and third quartiles also suggest large dispersion in most output elasticities and the rate of technical change. A comparison of the OLS elasticiticities with the mean semiparametric elasticities led to a number of differences, mainly, related to the output elasticities with respect to capacity utilization and wages. The other mean output elasticities differ marginally, while the rate of technical regress is lower in the semiparametric model. In sum, the results suggest presence of large heterogeneity in the plant's output response to changes in the production factors and technological change.

Similar to the large variations in the levels of output elasticities and marginal effects of various characteristics on production, there is also large variation in their averages across different generator characteristics and over time. The key factors of interest include: number of generators per plant, average age of generator in years, fuel source, plant type, facility load type, facility utilization rate, and holding time. Focusing at the changes in the mean output elasticities of inputs over time, we note that output elasticity with respect to 
facility capacity is declining over time, while the output elasticity with respect to fuel cost is increasing.

Large heterogeneity in output elasticities and marginal effects of plant characteristics over time and across different plant characteristics suggest that the volatile fuel price development, the high quasi fixed wage costs, difficulties in investment decision in new capacity considering the specific primary fuel types, as well as capacity distribution and utilization are the key issues to be considered in the strategy for improving the effectiveness of the fuel factor. The increased and volatile fuel price is likely to be the main source of productivity decrease. A reorganization of the electricity generation sector by the same fuel type can be a way to obtain high purchasing power and stability in fuel prices. It can also make the operational performance higher and organizational management easier.

\section{References}

Baek J. and H. Kim (2013), Is economic growth good or bad for the environment? Empirical evidence from Korea, Energy Economics 36, 744-749.

Choi K.H. and B.W. Ang (2002), Measuring Thermal Efficiency Improvement in Power Generation: The Divisia Decomposition Approach, Energy 27(5), 447-455.

Fan Y. and Q. Li (1996), Consistent Model Specification Tests: Omitted Variables and Semiparametric Functional Forms, Econometrica 65, 865-890.

Griliches Z. (1979), Issues in Assessing the Contribution of Research and Development to Productivity Growth, Bell Journal of Economics 10, 92-116.

Griliches Z. (1986), Productivity, R\&D and Basic Research at the Firm Level in the 1970's, American Economic Review 76, 141-154.

Hastie T. and R. Tibshirani (1993), Varying Coefficient Models, Journal of the Royal Statistical Society, Series B, 55, 757-796. 
Hayashi M. and L. Hughes (2013), The policy responses to the Fukushima nuclear accident and their effect on Japanese energy security, Energy Policy 59, 86-101.

HCC-SNUEL (2008), Final Report: Estimation of Success after Separation of the Electricity Generation, Horwath Choongjung Consulting Corporation and Seoul National University Engineering Research Institute.

Heshmati A. (2012), Economic Fundamentals of Power Plants Performance, Routledge Studies in the Modern World Economy \#97, Routledge.

Heshmati A. (2013a), Demand, Customer Base-Line and Demand Response in the Electricity Market: A Survey, Journal of Economics Surveys, forthcoming.

Heshmati A. (2013b), Efficiency and Productivity Impacts of Restructuring the Korean Electricity Generation, Korea and the World Economy 14(1), 000-000.

Huh S. and C. Lee (2014), Diffusion of renewable energy technologies in South Korea on introducing their competitive interrelationships, Energy Policy 69, 248-257.

Kim H., E. Shin and W. Chung (2011), Energy demand and supply, energy policies, and energy security in Republic of Korea, Energy Policy 39(11), 6882-6897.

Kim T., D. Lee and S. Koo (2014), Determining the scale of R7D investment for renewable energy in Korea using a comparative analogy approach, Renewable and Sustainable Energy Review 37, 307-317.

Lee B.H. and H.H. Ahn (2006), Electricity Industry Restructuring Revisited: The Case of Korea, Energy Policy 34(10), 1115-1126.

Li Q., C. Huang, D. Li and T. Fu (2002), Semiparametric Smooth Coefficient Models, Journal of Business Economics and Statistics 20, 412-422.

Li Q. and J. Racine (2007), Nonparametric Econometrics: Theory and Practice, Princeton University Press, Princeton.

Li Q. and J. Racine (2010), Smooth Varying-Coefficient Estimation and Inference for Qualitative and Quantitative Data, Econometric Theory 26, 1607-1637.

Min D. and J. Chung (2013), Evaluation of the long-term power generation mix: The case study of South Korea's energy policy, Energy Policy 62, 1544-1552. 
MKE (2008a), The First Basic Plan of National Energy, Ministry of Knowledge Economy, 08.27.2008.

MKE (2008b), The $4^{\text {th }}$ Basic Plan of Long-Term Electricity Supply and Demand (20082022), http://www.scribd.com/doc/51969530/The-4th-Basic-Plan-of-Long-TermElectricity-Supply-and-Demand-Korea, accessed June 26, 2014.

Park S.U. and J.B. Lesourd (2000), The Efficiency of Conventional Fuel Power Plants in South Korea: A Comparison of Parametric and Non-Parametric Approaches, International Journal of Production Economics 63(1), 59-67.

Park E. and Y. Ohm (2014), Factors influencing the public intention to use renewable energy technologies in South Korea: Effects of the Fukushima nuclear accident, Energy Policy 65, 198-211.

Racine J. and Q. Li (2004), Nonparametric Estimation of Regression Functions with both Categorical and Continuous Data, Journal of Econometrics 119, 99-130.

Robinson P.M. (1988), Root-N-Consistent Semiparametric Regression, Econometrica 56, 931-954.

Ryu H., S. Dorjragchaa, Y. Kim and K. Kim (2014), Electricity-generation mix considering energy security and carbon emission mitigation: Case of Korea and Mongolia, Energy 64(1), 1071-1079.

Shin J., J. Woo, S. Huh, J. Lee and G. Jeong (2014), Analyzing public preferences and increasing acceptability for the renewable portfolio standard in Korea, Energy Economics 42, 17-26.

Stock J.H. (1989), Nonparametric Policy Analysis, Journal of the American Statistical Association 84, 567-575.

Suk S., X. Liu, S. Lee, S. Go and K. Sudo (2014), Affordability of energy cost increases for Korean companies due to market-based climate policies: A survey study by sector, Journal of Cleaner Production 67(15), 208-219. 
Zhang R., K. Sun, M.S. Delgado and S.C. Kumbhakar (2012), Productivity in China's High Technology Industry; Regional Heterogeneity and R\&D, Technological Forecasting and Social Change 79, 127-141. 


\begin{tabular}{|l|c|c|c|c|c|c|c|c|}
\hline Table 2A. Summary statistics of output elasticities wrt inputs X \\
\hline Dep. Var. = log Elec Gen & Intercept & Fac Cap & $\begin{array}{c}\text { Main. } \\
\text { Cost }\end{array}$ & SalManExp & FuelCost & OthCost & Wages & time \\
\hline OLS: & & & & & & & & \\
\hline & 12.5610 & 0.7803 & 0.0702 & 0.2402 & 0.6274 & 0.0800 & -0.1435 & -0.0510 \\
\hline & $(0.1536)$ & $(0.0297)$ & $(0.0173)$ & $(0.0258)$ & $(0.0203)$ & $(0.0326)$ & $(0.0386)$ & $(0.0057)$ \\
\hline Semiparametric: & & & & & & & & \\
\hline Mean & 3.9590 & 0.5582 & -0.0089 & 0.2547 & 0.4432 & 0.0828 & -0.0117 & -0.0611 \\
\hline & $(0.1316)$ & $(0.0172)$ & $(0.0037)$ & $(0.0086)$ & $(0.0138)$ & $(0.0139)$ & $(0.0138)$ & $(0.0042)$ \\
\hline $25 \%$ & 1.6460 & 0.2165 & -0.0802 & 0.1565 & 0.2578 & -0.1575 & -0.2599 & -0.0805 \\
\hline & $(0.0594)$ & $(0.0110)$ & $(0.0029)$ & $(0.0046)$ & $(0.0063)$ & $(0.0064)$ & $(0.0027)$ & $(0.0027)$ \\
\hline Median & 3.1970 & 0.6186 & -0.0171 & 0.1739 & 0.4694 & 0.0810 & 0.0768 & -0.0432 \\
\hline & $(0.0532)$ & $(0.0127)$ & $(0.0020)$ & $(0.0009)$ & $(0.0086)$ & $(0.0047)$ & $(0.0037)$ & $(0.0010)$ \\
\hline $75 \%$ & 5.4570 & 0.9019 & 0.0332 & 0.3135 & 0.7571 & 0.2501 & 0.1354 & -0.0253 \\
\hline & $(0.1419)$ & $(0.0359)$ & $(0.0014)$ & $(0.0470)$ & $(0.0256)$ & $(0.0031)$ & $(0.0050)$ & $(0.0006)$ \\
\hline
\end{tabular}

Notes: Standard errors are in parentheses.

factyp $=1$, dfaccap $=0$, dreafuecos $=0$, dwage $=0$ are base categories . 


\begin{tabular}{|l|c|c|c|c|c|c|c|}
\hline \multicolumn{7}{|l|}{ Table 2B. Summary statistics of partial derivatives of log electricity generation with respect to Characteristics Z } \\
\hline Dep. Var. = log Elec Gen & No Gen & Age & FacType 2 & FacType 3 & DFacCap & DFuelCost & Dwages \\
\hline OLS: & & & & & & & \\
\hline & -0.1710 & 0.0056 & -0.3274 & -0.7786 & -3.9403 & -6.3124 & -0.2423 \\
\hline & $(0.0210)$ & $(0.0018)$ & $(0.0662)$ & $(0.0626)$ & $(0.1845)$ & $(0.1950)$ & $(0.2486)$ \\
\hline Semiparametric: & & & & & & & \\
\hline Mean & -0.0064 & -0.0013 & -0.2151 & -0.4726 & 0.1531 & -0.7526 & 0.0100 \\
\hline & $(0.0008)$ & $(0.0006)$ & $(0.0136)$ & $(0.0195)$ & $(0.0362)$ & $(0.0572)$ & $(0.0275)$ \\
\hline $25 \%$ & -0.0033 & -0.0101 & -0.4261 & -0.8777 & -0.0002 & -0.5766 & -0.2546 \\
\hline & $(0.0001)$ & $(0.0003)$ & $(0.0142)$ & $(0.0315)$ & $(0.0017)$ & $(0.0174)$ & $(0.0100)$ \\
\hline Median & 0.0000 & 0.0003 & -0.1817 & -0.4307 & 0.0000 & -0.0112 & -0.0240 \\
\hline & $(0.0000)$ & $(0.0002)$ & $(0.0096)$ & $(0.0113)$ & $(0.0000)$ & $(0.0017)$ & $(0.0069)$ \\
\hline $75 \%$ & 0.0001 & 0.0106 & 0.0000 & -0.0145 & 0.0083 & 0.3014 & 0.2182 \\
\hline & $(0.0001)$ & $(0.0004)$ & $(0.0066)$ & $(0.0101)$ & $(0.0009)$ & $(0.0177)$ & $(0.0061)$ \\
\hline
\end{tabular}

Notes: Standard errors are in parentheses.

factyp $=1$, dfaccap $=0$, dreafuecos $=0$, dwage $=0$ are base categories . 


\begin{tabular}{|c|c|c|c|c|c|c|c|c|}
\hline \multicolumn{9}{|c|}{ Table 3A. Mean semiparametric output elasticity with respect to inputs $X$} \\
\hline & Intercept & $\begin{array}{l}\text { Facility } \\
\text { Capacity }\end{array}$ & $\begin{array}{l}\text { Mainten- } \\
\text { ance Cost }\end{array}$ & $\begin{array}{l}\text { Sales } \\
\text { and Man } \\
\text { Exp }\end{array}$ & $\begin{array}{l}\text { Fuel } \\
\text { Cost }\end{array}$ & $\begin{array}{l}\text { Other } \\
\text { Costs }\end{array}$ & Wages & Technology \\
\hline \multicolumn{9}{|c|}{ Year of operation: } \\
\hline 1995 & 4.989 & 0.612 & -0.036 & 0.362 & 0.371 & -0.019 & -0.009 & -0.067 \\
\hline 1996 & 5.246 & 0.566 & -0.056 & 0.364 & 0.363 & -0.011 & 0.005 & -0.078 \\
\hline 1997 & 4.306 & 0.591 & -0.022 & 0.283 & 0.431 & -0.005 & 0.053 & -0.075 \\
\hline 1998 & 4.258 & 0.579 & -0.016 & 0.284 & 0.433 & -0.030 & 0.091 & -0.076 \\
\hline 1999 & 3.934 & 0.579 & -0.009 & 0.270 & 0.436 & 0.092 & -0.039 & -0.052 \\
\hline 2000 & 3.822 & 0.565 & -0.006 & 0.257 & 0.445 & 0.094 & -0.019 & -0.054 \\
\hline 2001 & 3.799 & 0.560 & -0.003 & 0.248 & 0.453 & 0.080 & 0.002 & -0.058 \\
\hline 2002 & 3.591 & 0.540 & -0.003 & 0.213 & 0.467 & 0.152 & -0.047 & -0.060 \\
\hline 2003 & 3.705 & 0.534 & -0.001 & 0.215 & 0.468 & 0.130 & -0.032 & -0.064 \\
\hline 2004 & 3.488 & 0.541 & 0.008 & 0.207 & 0.468 & 0.143 & -0.043 & -0.049 \\
\hline 2005 & 3.516 & 0.533 & 0.009 & 0.208 & 0.467 & 0.148 & -0.044 & -0.052 \\
\hline 2006 & 3.446 & 0.523 & 0.009 & 0.204 & 0.478 & 0.152 & -0.037 & -0.056 \\
\hline \multicolumn{9}{|c|}{ Number of Generators: } \\
\hline 0 & 9.394 & 0.478 & -0.152 & 0.636 & 0.347 & -0.238 & 0.021 & -0.300 \\
\hline 1 & 3.736 & 0.614 & 0.000 & 0.253 & 0.375 & 0.149 & -0.047 & -0.038 \\
\hline 2 & 3.578 & 0.337 & -0.049 & 0.285 & 0.692 & -0.052 & 0.035 & -0.072 \\
\hline 3 & 3.528 & 0.392 & -0.032 & 0.217 & 0.770 & -0.161 & 0.074 & -0.066 \\
\hline 4 & 5.480 & 0.353 & 0.041 & 0.428 & 0.603 & -0.082 & -0.139 & -0.081 \\
\hline 5 & 6.398 & 0.197 & -0.046 & 0.238 & 0.735 & -0.509 & 0.460 & -0.234 \\
\hline 6 & 5.068 & 0.278 & -0.081 & 0.207 & 0.779 & -0.063 & -0.130 & -0.058 \\
\hline 7 & 16.079 & -0.100 & 0.017 & -0.858 & 0.695 & -0.787 & 1.834 & -1.491 \\
\hline 8 & 14.903 & 0.109 & -0.023 & -0.186 & 1.005 & -0.839 & 1.485 & -1.329 \\
\hline \multicolumn{9}{|c|}{ Generator Age: } \\
\hline $0-6$ years & 2.124 & 0.632 & -0.019 & 0.219 & 0.585 & 0.047 & 0.085 & -0.062 \\
\hline $7-20$ years & 3.871 & 0.574 & -0.052 & 0.243 & 0.470 & 0.104 & 0.052 & -0.090 \\
\hline $21+$ years & 5.587 & 0.481 & 0.044 & 0.296 & 0.297 & 0.091 & -0.158 & -0.030 \\
\hline \multicolumn{9}{|l|}{ Fuel Source: } \\
\hline Nuclear & 2.368 & 0.892 & -0.043 & 0.169 & 0.367 & 0.154 & 0.107 & -0.036 \\
\hline Hydro & 7.027 & 0.598 & -0.003 & 0.455 & 0.107 & -0.077 & -0.129 & 0.004 \\
\hline Oil & 3.705 & 0.199 & 0.060 & 0.142 & 0.707 & 0.089 & 0.103 & -0.180 \\
\hline $\begin{array}{l}\text { Coal } \\
\text { Anthracite }\end{array}$ & 2.698 & 0.841 & -0.014 & 0.192 & 0.321 & 0.144 & 0.165 & -0.078 \\
\hline $\begin{array}{l}\text { Coal } \\
\text { Bituminous }\end{array}$ & 2.086 & 0.868 & -0.020 & 0.173 & 0.398 & 0.149 & 0.105 & -0.042 \\
\hline LNG & 3.525 & 0.262 & -0.037 & 0.247 & 0.731 & 0.145 & -0.175 & -0.071 \\
\hline
\end{tabular}




\begin{tabular}{|c|c|c|c|c|c|c|c|c|}
\hline & Intercept & $\begin{array}{l}\text { Facility } \\
\text { Capacity }\end{array}$ & $\begin{array}{l}\text { Mainten- } \\
\text { ance Cost }\end{array}$ & $\begin{array}{l}\text { Sales } \\
\text { and Man } \\
\text { Exp }\end{array}$ & $\begin{array}{l}\text { Fuel } \\
\text { Cost }\end{array}$ & $\begin{array}{l}\text { Other } \\
\text { Costs }\end{array}$ & Wages & Technology \\
\hline \multicolumn{9}{|l|}{ Plant Type: } \\
\hline Nuclear & 2.368 & 0.892 & -0.043 & 0.169 & 0.367 & 0.154 & 0.107 & -0.036 \\
\hline Intl comb. & 8.481 & 0.667 & 0.023 & 0.505 & -0.065 & -0.207 & -0.095 & 0.028 \\
\hline Gas turbine & 3.705 & 0.199 & 0.060 & 0.142 & 0.707 & 0.089 & 0.103 & -0.180 \\
\hline Comb. cycle & 2.698 & 0.841 & -0.014 & 0.192 & 0.321 & 0.144 & 0.165 & -0.078 \\
\hline Hydro & 2.086 & 0.868 & -0.020 & 0.173 & 0.398 & 0.149 & 0.105 & -0.042 \\
\hline Hydro pump & 1.953 & 0.357 & -0.093 & 0.280 & 0.706 & 0.377 & -0.247 & -0.082 \\
\hline Hydro small & 3.525 & 0.262 & -0.037 & 0.247 & 0.731 & 0.145 & -0.175 & -0.071 \\
\hline \multicolumn{9}{|l|}{ Facility Type: } \\
\hline Base load & 2.271 & 0.872 & -0.027 & 0.175 & 0.376 & 0.150 & 0.115 & -0.045 \\
\hline Mid load & 3.705 & 0.199 & 0.060 & 0.142 & 0.707 & 0.089 & 0.103 & -0.180 \\
\hline Peak load & 5.365 & 0.439 & -0.019 & 0.356 & 0.403 & 0.029 & -0.151 & -0.032 \\
\hline \multicolumn{9}{|c|}{ Capacity Utilization: } \\
\hline$-95.0 \%$ & 3.214 & 0.591 & 0.041 & 0.198 & 0.453 & 0.104 & 0.062 & -0.083 \\
\hline $951.0-97.8 \%$ & 2.632 & 0.611 & -0.030 & 0.189 & 0.535 & 0.182 & -0.007 & -0.064 \\
\hline $97.9-\%$ & 6.203 & 0.466 & -0.043 & 0.388 & 0.334 & -0.045 & -0.100 & -0.034 \\
\hline \multicolumn{9}{|c|}{ Holding Time: } \\
\hline 0 hours & 5.492 & 0.710 & -0.003 & 0.326 & 0.213 & -0.057 & 0.058 & -0.049 \\
\hline $\begin{array}{l}1-1500 \\
\text { hours }\end{array}$ & 2.428 & 0.698 & -0.011 & 0.188 & 0.449 & 0.180 & 0.061 & -0.061 \\
\hline 1501- hours & 3.215 & 0.254 & -0.015 & 0.216 & 0.732 & 0.185 & -0.158 & -0.077 \\
\hline \multicolumn{9}{|l|}{ Sample: } \\
\hline Mean & 3.959 & 0.558 & -0.009 & 0.255 & 0.443 & 0.083 & -0.012 & -0.061 \\
\hline Std Dev & 3.301 & 0.388 & 0.149 & 0.248 & 0.330 & 0.559 & 0.548 & 0.156 \\
\hline
\end{tabular}




\begin{tabular}{|c|c|c|c|c|c|c|c|}
\hline & $\begin{array}{l}\text { Number } \\
\text { of } \\
\text { Generator }\end{array}$ & $\begin{array}{l}\text { Generator } \\
\text { Age }\end{array}$ & $\begin{array}{l}\text { Facility } \\
\text { Type } 2 \\
\text { Midload }\end{array}$ & $\begin{array}{l}\text { Facility } \\
\text { Type } 3 \\
\text { Peakload } \\
\end{array}$ & $\begin{array}{l}\text { Facility } \\
\text { Capacity } \\
\text { Dummy }\end{array}$ & $\begin{array}{l}\text { Fuel Cost } \\
\text { Dummy }\end{array}$ & $\begin{array}{l}\text { Wages } \\
\text { Dummy }\end{array}$ \\
\hline \multicolumn{8}{|c|}{ Year of operation: } \\
\hline 1995 & 0.003 & 0.007 & 0.019 & -0.248 & -0.018 & -0.362 & -0.119 \\
\hline 1996 & -0.004 & 0.008 & 0.037 & -0.145 & -0.245 & -0.443 & 0.089 \\
\hline 1997 & -0.007 & 0.006 & -0.103 & -0.288 & 0.136 & -0.391 & -0.099 \\
\hline 1998 & -0.011 & 0.002 & -0.255 & -0.512 & 0.151 & -0.711 & -0.138 \\
\hline 1999 & -0.008 & -0.002 & -0.205 & -0.523 & 0.142 & -0.708 & -0.024 \\
\hline 2000 & -0.012 & -0.002 & -0.173 & -0.491 & 0.102 & -0.785 & -0.006 \\
\hline 2001 & -0.014 & -0.001 & -0.262 & -0.543 & 0.081 & -0.770 & 0.130 \\
\hline 2002 & -0.007 & 0.001 & -0.229 & -0.527 & 0.213 & -0.882 & 0.089 \\
\hline 2003 & -0.006 & -0.002 & -0.270 & -0.525 & 0.259 & -0.867 & 0.157 \\
\hline 2004 & -0.004 & -0.006 & -0.317 & -0.587 & 0.275 & -0.898 & 0.052 \\
\hline 2005 & -0.004 & -0.009 & -0.327 & -0.577 & 0.276 & -0.921 & -0.006 \\
\hline 2006 & -0.002 & -0.009 & -0.365 & -0.569 & 0.327 & -1.061 & -0.042 \\
\hline \multicolumn{8}{|c|}{ Number of Generators: } \\
\hline 0 & 0.000 & 0.000 & 0.143 & 0.400 & -1.384 & -0.906 & -0.791 \\
\hline 1 & -0.002 & -0.001 & -0.195 & -0.489 & 0.212 & -0.945 & 0.007 \\
\hline 2 & -0.002 & 0.017 & -0.330 & -0.428 & -0.111 & -0.002 & 0.228 \\
\hline 3 & -0.027 & -0.013 & -0.370 & -0.613 & 0.152 & 0.121 & 0.136 \\
\hline 4 & -0.055 & -0.044 & -0.019 & -0.133 & -0.083 & -0.207 & -0.514 \\
\hline 5 & -0.054 & -0.014 & -0.427 & -0.777 & 0.137 & 0.176 & -0.297 \\
\hline 6 & -0.044 & -0.003 & -0.301 & -0.812 & -0.005 & 0.289 & 0.171 \\
\hline 7 & -0.013 & -0.017 & -0.121 & -0.659 & 0.011 & -0.007 & -2.509 \\
\hline 8 & -0.099 & -0.016 & -0.138 & 1.538 & 0.113 & 0.005 & 1.086 \\
\hline \multicolumn{8}{|c|}{ Generator Age: } \\
\hline $0-6$ years & -0.010 & 0.002 & -0.264 & -0.774 & -0.075 & -0.182 & 0.083 \\
\hline $7-20$ years & -0.007 & -0.002 & -0.322 & -0.519 & -0.006 & -0.191 & -0.059 \\
\hline $21+$ years & -0.002 & -0.004 & -0.064 & -0.173 & 0.508 & -1.806 & 0.020 \\
\hline \multicolumn{8}{|l|}{ Fuel Source: } \\
\hline Nuclear & 0.001 & 0.003 & -0.443 & -1.128 & 0.010 & 0.418 & 0.061 \\
\hline Hydro & -0.003 & -0.001 & -0.112 & -0.241 & 0.689 & -3.088 & 0.175 \\
\hline Oil & -0.011 & -0.006 & -0.080 & -0.062 & -0.014 & -0.080 & -0.225 \\
\hline $\begin{array}{l}\text { Coal } \\
\text { Anthracite }\end{array}$ & 0.000 & 0.005 & -0.044 & -0.117 & -0.024 & -0.201 & -0.301 \\
\hline $\begin{array}{l}\text { Coal } \\
\text { Bituminous }\end{array}$ & -0.002 & 0.001 & -0.264 & -0.718 & 0.033 & -0.161 & -0.070 \\
\hline LNG & -0.016 & -0.004 & -0.309 & -0.560 & -0.094 & 0.068 & 0.120 \\
\hline
\end{tabular}




\begin{tabular}{|c|c|c|c|c|c|c|c|}
\hline & $\begin{array}{l}\text { Number } \\
\text { of } \\
\text { Generator }\end{array}$ & $\begin{array}{l}\text { Generator } \\
\text { Age }\end{array}$ & $\begin{array}{l}\text { Facility } \\
\text { Type } 2 \\
\text { Midload } \\
\end{array}$ & $\begin{array}{l}\text { Facility } \\
\text { Type } 3 \\
\text { Peakload } \\
\end{array}$ & $\begin{array}{l}\text { Facility } \\
\text { Capacity } \\
\text { Dummy }\end{array}$ & $\begin{array}{l}\text { Fuel Cost } \\
\text { Dummy }\end{array}$ & $\begin{array}{l}\text { Wages } \\
\text { Dummy }\end{array}$ \\
\hline \multicolumn{8}{|l|}{ Plant Type: } \\
\hline Nuclear & 0.001 & 0.003 & -0.443 & -1.128 & 0.010 & 0.418 & 0.061 \\
\hline Intl comb. & 0.000 & -0.001 & 0.162 & -0.012 & 0.905 & -3.577 & 0.239 \\
\hline Gas turbine & -0.011 & -0.006 & -0.080 & -0.062 & -0.014 & -0.080 & -0.225 \\
\hline Comb. cycle & 0.000 & 0.005 & -0.044 & -0.117 & -0.024 & -0.201 & -0.301 \\
\hline Hydro & -0.002 & 0.001 & -0.264 & -0.718 & 0.033 & -0.161 & -0.070 \\
\hline Hydro pump & -0.011 & -0.004 & -1.067 & -1.042 & -0.066 & -1.380 & -0.049 \\
\hline Hydro small & -0.016 & -0.004 & -0.309 & -0.560 & -0.094 & 0.068 & 0.120 \\
\hline \multicolumn{8}{|c|}{ Facility Type: } \\
\hline Base load & -0.001 & 0.002 & -0.288 & -0.758 & 0.017 & 0.020 & -0.063 \\
\hline Mid load & -0.011 & -0.006 & -0.080 & -0.062 & -0.014 & -0.080 & -0.225 \\
\hline Peak load & -0.009 & -0.002 & -0.205 & -0.393 & 0.317 & -1.590 & 0.149 \\
\hline \multicolumn{8}{|c|}{ Capacity Utilization: } \\
\hline$-95.0 \%$ & -0.004 & -0.003 & -0.139 & -0.463 & 0.072 & -0.223 & 0.131 \\
\hline $951.0-97.8 \%$ & -0.007 & 0.002 & -0.279 & -0.667 & -0.105 & 0.093 & -0.049 \\
\hline $97.9-\%$ & -0.008 & -0.002 & -0.233 & -0.277 & 0.517 & -2.244 & -0.064 \\
\hline \multicolumn{8}{|c|}{ Holding Time: } \\
\hline 0 hours & -0.002 & 0.001 & -0.126 & -0.462 & 0.432 & -1.648 & 0.087 \\
\hline $\begin{array}{l}1-1500 \\
\text { hours }\end{array}$ & -0.004 & 0.002 & -0.146 & -0.419 & 0.012 & 0.010 & -0.195 \\
\hline 1501- hours & -0.014 & -0.006 & -0.384 & -0.528 & -0.091 & -0.214 & 0.075 \\
\hline \multicolumn{8}{|l|}{ Sample: } \\
\hline Mean & -0.006 & -0.001 & -0.215 & -0.473 & 0.153 & -0.753 & 0.010 \\
\hline Std Dev & 0.031 & 0.026 & 0.534 & 0.637 & 1.451 & 2.198 & 1.110 \\
\hline
\end{tabular}

